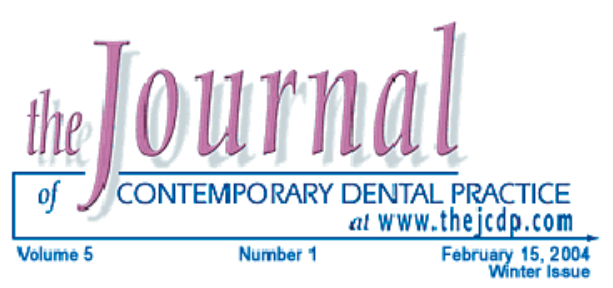

\title{
Shear Bond Strengths and Microleakage of Four Types of Dentin Adhesive Materials
}

\section{Nasrien Z. Ateyah, BDS, MSc; Ahmed A. Elhejazi, BDS, MSc, PhD}

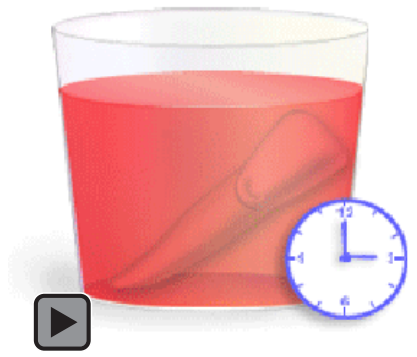

Abstract

The aim of this investigation was to compare the microleakage of composite resin (Z-100) and shear bond strength to bovine dentin using different types of adhesive systems (Scotch Bond Multi-Purpose, All-Bond 2, One-Step, and Perma Quick) to compare and correlate microleakage to shear bond strength. For the microleakage aspect of the study, 20 class $V$ were prepared (bovine incisors) with 90-degree cavosurface margins and were located at the cemento-enamel junction using a template. Each dentin bonding system was applied to five cavities following the manufacturer's instructions and restored with Z-100 composite resin. After 24 hours of storage in distilled water at $37^{\circ} \mathrm{C}$, the teeth were immersed in $2 \%$ basic fuchsin dye. All teeth were sectioned in a mesiodistal direction using a diamond saw, and each section was then inspected under a stereomacroscope. For the shear bond strength aspect of the study, 20 bovine incisors were centrally horizontally mounted in Teflon mold with cold cure acrylic resin. Flat labial dentin surfaces were prepared using different grit silicon carbide abrasive wheels. Five specimens were used for each of the bonding agent systems. Each specimen was bonded with restorative composite resin (Z-100) and applied to the treated dentinal surface through a split Teflon mold. All specimens were stored in distilled water at $37^{\circ} \mathrm{C}$ for 24 hours. The bonds were stressed using shear forces at a crosshead speed of $0.5 \mathrm{~mm} / \mathrm{min}$ using an Instron Universal testing machine.

Findings indicate none of the systems tested in this study were free from microleakage. Scotch bond multipurpose achieved the best seal, with One-Step being second best, while All-Bond 2 and Perma Quick had the poorest seal. However, there were significant differences among the shear bond strengths of the four bonding systems tested. Scotch Bond Multi-Purpose has a higher bond strength to composite resin when compared to the other dentin adhesives. The study also concluded there is no association between microleakage and shear bond strength.

Keywords: Composite, shear bond, microleakage, adhesive, bonding agents, dentin

Citation: Ateyah AZ, Elhejazi AA. Shear Bond Strengths and Microleakage of Four Types of Dentin Adhesive Materials. J Contemp Dent Pract 2004 February;(5)1:063-073.

(C) Seer Publishing 


\section{Introduction}

The demand for esthetic restorations and alternative materials to replace amalgam restorations has driven the search for tooth-colored materials to fulfill the requirement for physical properties of amalgam. To fulfill these requirements, resin bonded-composite has been introduced as an alternative restorative material to amalgam for posterior teeth. ${ }^{1,2,3}$ The success of these restorations depends on bonding them to hard tooth tissue that will retain the restoration to the cavity preparation and prevent microleakage. ${ }^{3,4,5}$

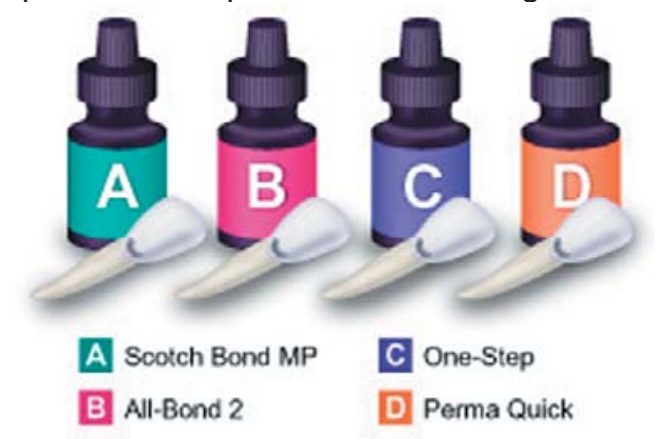

The enamel etching technique has provided an ideal surface for reliable bonding performance using adhesive resin. ${ }^{6}$ However, bonding to dentin has a less reliable result due to the characteristics of dentin (organic content, tubular structure, and presence of outward fluid movement). ${ }^{1,7}$ Dentin bonding agents have improved over the past ten years in an attempt to overcome these difficulties and are now available in single-bottle systems to facilitate the ease of use. ${ }^{8}$

Different adhesive systems have been introduced that provide bonding between tooth-colored filling materials and tooth structure (dentin) that will withstand the contraction forces generated by polymerization shrinkage while maintaining a marginal seal during functioning of the restored tooth. ${ }^{3}$

Recently, new dentin bonding agents have been introduced to the market as single bottle systems that manufacturers claim produce good bonding to dentin while being less technique sensitivity than multi-bottle systems. The purpose of this investigation was three-fold:

1. To study the microleakage and the shear bond strength of composite resin to bovine dentin using different types of adhesive systems.
2. To compare microleakage with bonding strength.

3. To examine if there is any relation between microleakage and shear bond strength.

\section{Material and Methods}

\section{Specimen Preparation}

1. Microleakage

Twenty freshly extracted bovine incisors were cleaned, using a scalpel, and examined to ensure there were no cracks or fractures, especially in the sites to be restored. These were stored in de-ionized water with an anti-bactericidal agent, $0.2 \%$ sodium azide, until ready for use.

Before preparing the teeth for resin placement the specimens were cleaned with a rubber cup and slurry of pumice. Standardized class V cavity preparations were placed in the buccal surface at the cemento-enamel junction. The preparations were made to a uniform kidney shaped outline using a template. A \#329 carbide bur (Midwest Dental Product Corp., Des Plaines IL, USA) in a high-speed handpiece with air-water spray was used. The preparation measured $5 \mathrm{~mm}$ long, $3 \mathrm{~mm}$ wide, and $2 \mathrm{~mm}$ deep which was determined by the entry of the bur, with the incisal margin in enamel and the gingival margin in cementum. The teeth were then randomly divided into four groups; each group contained five restorations. After completion of the preparations, the bonding agents (Scotch Bond Multi-Purpose, All-Bond 2, OneStep, and Perma Quick) were applied according to the manufacturers' directions (Table 1).

All preparations were filled with Z-100 (3M Dental Products, St. Paul, Illinois, MN 55144, 1000) composite resins and light cured for 40 seconds (ESPE Dental Elipar Highlight, Seefeld, Germany). Then, all specimens were stored in distilled water at $37^{\circ} \mathrm{C}$ for 24 hours.

\section{Microleakage Evaluation}

All groups were prepared for microleakage evaluation by coating the complete tooth with one application of nail varnish, except for $1 \mathrm{~mm}$ around the restoration margins. The apices of the teeth were sealed with Z100 light activated composite and Scotchbond Multipurpose used as an adhesive agent. Then all apical areas 
Table 1. Materials, manufacturers and procedures.

\begin{tabular}{|c|c|c|}
\hline Material & Manufacturer & Procedure \\
\hline Scotch Bond MP (SBMP) & $\begin{array}{l}\text { 3M Dental Products } \\
\text { St. Paul, MN 55144, } 1000\end{array}$ & $\begin{array}{l}\text { Etchant: apply } 15 \mathrm{~s} . \text {, rinse } 15 \mathrm{~s} . \\
\text { and dry } 5 \mathrm{~s} \text {. } \\
\text { Primer: apply one coat, dry } 5 \mathrm{~s} \text {. } \\
\text { Adhesive: apply one coat, cure } 20 \mathrm{~s} \text {. }\end{array}$ \\
\hline All-Bond 2 & Bisco Inc. Illinois 60193 & $\begin{array}{l}\text { Conditioner: apply } 15 \text { s., rinse } \\
\text { and dry } 1 \text { s. } \\
\text { Primer: apply } 5 \text { coats, dry } 5 \text { s. D/E } \\
\text { Resin: apply a thin layer, light cure } 20 \\
\text { s. }\end{array}$ \\
\hline One-Step & Bisco Inc. Illinois 60193 & $\begin{array}{l}\text { Conditioner: apply } 15 \text { s., rinse } \\
\text { and dry. } \\
\text { Adhesive: apply } 2 \text { drops, } 2 \text { coats, dry } \\
10 \text { s., light cure } 10 \mathrm{~s} \text {. }\end{array}$ \\
\hline Perma Quick (PQ 1) & $\begin{array}{l}\text { Ultradent Product, } \\
\text { South Jordan, Utah } 84095\end{array}$ & $\begin{array}{l}\text { Conditioner: apply } 15 \text { s., rinse } 5 \mathrm{~s} . \\
\text { and dry } 1 \mathrm{~s} \text {. } \\
\text { Bonding: apply } 15 \mathrm{~s} \text {. air thinning, } \\
\text { light cure } 20 \mathrm{~s} \text {. }\end{array}$ \\
\hline
\end{tabular}

were covered with a varnish seal. The specimens were then placed in a $2 \%$ basic Fuchsin dye solution (Fisher Scientific, Fair Lawn, NJ, USA) for 24 hours at room temperature, then rinsed with running tap water for 5 minutes. The specimens were then embedded in a cavity that was made inside cork that was then filled with paraffin wax to hold the specimens and stored in a refrigerator.

Each tooth was sectioned in a mesiodistal direction at four different locations making a total of 20 specimens for each dentin adhesive system using a slow speed, water-cooled diamond saw (Saw Microtome, Leitz-Leica, Germany). The sections produced were then separated and fixed on a glass slide and the cut surfaces were examined at the incisal and gingival margins under a stereomacroscope (Wild Photomakroskop, M400, Heerbrugg, Switzerland), at a $3.6 \times 1.25$ magnification.
The staining along the tooth restoration interface was based on the degree of dye penetration. The specimens were evaluated based on the graded scoring system with rating values of $0-3$. The rating was defined as follows:

$0=$ no leakage

$1=$ dye penetration less than half way to the axial wall

$2=$ dye penetration greater than half way to the axial wall

$3=$ dye penetration along the axial wall

The incisal and gingival scores for each group of restorations were compared using non-parametric statistical tests using Kruskal-Wallis. Mean shear bond strength values for each group were calculated and subjected to statistical analysis with one-way ANOVA at a 0.05 level of significance. Significant differences between the groups were determined with the Tukey (HSD) test. Incisal and gingival mean scores for each group were combined and compared using the Wilcoxon matched pairs signed rank test.

\section{Shear Strength}

A total of 20 bovine incisor teeth were used in this study. The roots of the teeth were cut and removed. The teeth were stored in de-ionized water until they were ready to be used. The facial surfaces were ground flat to expose dentin with 240 and 400 grit silicon carbide abrasive mounted 
on a grinding wheel with copious amounts of water (Jean Wirtz Automat A polishing machine Dusseldort, West Germany). The flattened surfaces of each tooth were centered flush horizontally in $35 \mathrm{~mm}$ diameter and $25 \mathrm{~mm}$ depth Teflon molds and held in place with cold cure acrylic resin. Before the bonding procedure, the teeth were again ground slightly using 600-grit silicon carbide abrasive paper to assure clean and fresh surfaces for bonding and to remove any acrylic flashes from the dentin surfaces.

The prepared 20 teeth were divided into four groups. Five specimens for each of the bonding agent systems were bonded according to the manufacturer's instructions with restorative composite resin (Z-100) (Table 1) and applied to the treated dentinal surface through a split Teflon mold, $6 \mathrm{~mm}$ in diameter that contacted the surface and extended approximately $3 \mathrm{~mm}$ from the surface, which was firmly attached to the tooth with a metal ring. Then the split mold was removed immediately after curing of the restoration. All specimens were then stored in distilled water for 24 hours at $37^{\circ} \mathrm{C}$.

The shear bond strengths were determined using an Instron Universal Testing Machine (Instron Cor. 8500

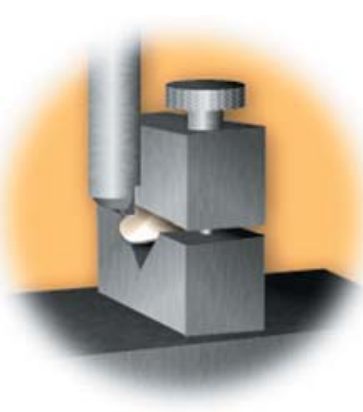
Canton, Massachusetts, USA) at a across head speed of $0.5 \mathrm{~mm}$ per minute. A knife-edge shear probe was attached to the cross head. Shear forces were recorded when the fracture occurred directly from the computer software in MPa.

\section{Results}

Microleakage scores of the four bonding agents at the gingival/incisal areas were recorded. Mean scores are shown in Tables 2 and 3, respectively. The mean values for microleakage scoring (Table 3) indicated that Scotch Bond Multi-Purpose had the lowest mean scale value (lowest leakage) on microleakage (0.3) in the incisal sample margin and (0.5) in the gingival sample margin, while One-Step had the second lowest mean score value 1.1 and 2.0 in incisal and gingival samples, respectively. All-Bond and Perma Quick had the highest mean scale values ranked third and fourth (2.3 and 2.5) in incisal margin samples. For the gingival margin samples, the mean score values were 2.45 (All-Bond) and 2.6 (Perma Quick).

Scotch Bond Multi-purpose adhesive showed a significantly $(p<0.05)$ higher shear bond strength (13.72 MPa) compared with Perma Quick (8.45 $\mathrm{MPa}$ ), All-Bond 2 (6.85), and One-Step (4.32 $\mathrm{MPa}$ ). No significant differences were found between $(P<0.05)$ Perma Quick and All-Bond 2 and also between All-Bond 2 and One-Step. Scotch Bond Multi-Purpose adhesive had the highest shear bonding strength value followed by Perma Quick and All-Bond 2 which are an intermediate range, and One-Step was the least.

\section{Discussion}

Enamel and dentin adhesives were introduced for two purposes:

The first purpose was to prevent the marginal gap at tooth-restoration interface. Microleakage was the parameter selected to study the gap formation. However, none of the adhesive systems tested in this study completely eliminated microle-

Table 2. Microleakage scores of the four bonding agents at the incisal and gingival margins.

\begin{tabular}{|c|c|c|c|c|c|c|c|c|c|c|}
\hline \multirow{3}{*}{ Material } & \multicolumn{5}{|c|}{$\begin{array}{c}\text { Microleakage Scores at } \\
\text { the Incisal Margin }\end{array}$} & \multicolumn{5}{|c|}{$\begin{array}{l}\text { Microleakage Scores at } \\
\text { the Gingival Margin }\end{array}$} \\
\hline & \multirow{2}{*}{ No. } & \multicolumn{4}{|c|}{ Scores } & \multirow{2}{*}{ No. } & \multicolumn{4}{|c|}{ Scores } \\
\hline & & 0 & 1 & 2 & 3 & & 0 & 1 & 2 & 3 \\
\hline $\begin{array}{l}\text { Scotch Bond } \\
\text { Multi-Purpose }\end{array}$ & 20 & 17 & 1 & 1 & 1 & 20 & 14 & 4 & 0 & 2 \\
\hline One-Step & 20 & 5 & 11 & 1 & 3 & 20 & 3 & 5 & 1 & 11 \\
\hline All-Bond 2 & 20 & 0 & 4 & 6 & 10 & 20 & 0 & 3 & 5 & 12 \\
\hline Perma Quick & 20 & 0 & 1 & 8 & 11 & 20 & 0 & 1 & 6 & 13 \\
\hline
\end{tabular}


Table 3. The bond strength and microleakage of materials tested.

\begin{tabular}{|l|c|c|c|}
\hline Materials & $\begin{array}{c}\text { Bond Strength } \\
(\mathrm{MPa})\end{array}$ & \multicolumn{2}{c|}{$\begin{array}{c}\text { Microleakage } \\
\text { (mean Scale) }\end{array}$} \\
\hline Scotch Bond Multi-Purpose & $13.72 \pm 3.03$ & 0.3 & 0.5 \\
\hline One-Step & $4.32 \pm 0.27$ & 1.1 & 2.0 \\
\hline All-Bond 2 & $6.85 \pm 0.97$ & 2.3 & 2.45 \\
\hline Perma Quick & $8.45 \pm 2.28$ & 2.5 & 2.6 \\
\hline
\end{tabular}

Value connected by the line are not significantly different $(p=0.5)$

akage. The data in Table 3 showed Scotch Bond Multi-Purpose had the lowest microleakage mean scale value 0.3 incisal and 0.5 gingival and were superior to the other adhesive systems. This finding is in agreement with others. ${ }^{11,12}$ All materials showed the gingival area had higher value than the incisal materials. The increased microleakage in gingival areas was due to the lack of enamel structure available in gingival areas compared to incisal areas. ${ }^{6}$

The second purpose of an adhesive system is to retain (bond) a restoration with tooth structure and to resist any failure. Shear bond strength was selected as the parameter to measure how adhesive systems bond to the tooth structure. The data on shear bond strength (Table 3) showed Scotch Bond Multi Purpose had the highest value (13.72 MPa). The lowest value was obtained with the One-Step system (4.32 MPa), while Perma Quick and All-Bond 2 had values

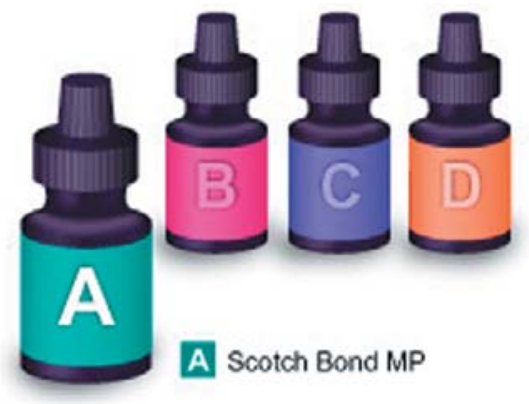

of ( 8.45 and $6.85 \mathrm{MPa})$ respectively and ranked as intermediate. There was no statistically significant difference between Perma Quick and All-Bond 2 and also between All-Bond 2 and OneStep (Table 3).

Bond strength and microleakage tests are in vitro studies designed to predict the clinical behavior of adhesive systems and some correlation may be expected between the two methods. ${ }^{23}$ The study did not show any correlation between bonding strength and microleakage. This is due to inconsistent data (microleakage and bond strength). For example, One-Step was second to Scotch Bond Multi Purpose in microleakage, while in shear bond strength One-Step was last. A material having higher shear bond strength does not necessarily mean it has low microleakage which is in agreement with Neme and co-workers. ${ }^{24}$ The reason for this phenomenon according to Sano et al. ${ }^{16}$ and $\mathrm{Li}$ et al. ${ }^{17}$ is leakage could happen through a porous zone at the hybrid layer-adhesive interface without gap formation. Furthermore, they indicated adhesive systems do not completely permeate the demineralized dentin but left a hybrid layer with large amounts of porosity that allowed oral fluid to diffuse along the interface without affecting the strength of the restorations. However, Scotch Bond Multi Purpose was found to be superior with regard to microleakage and bond strengths, which was in agreement with other studies. ${ }^{16,17,18}$

The performance of multi-step types of adhesive systems that are available in the market today was also examined. All of these systems depend on procedures using etching, primer, and bonding agents. One system was introduced to simplify the bonding procedure by combining the primer and the adhesive resin. Perma Quick and One-Step are two examples of this type of system. One bottle adhesive total etching (Perma Quick and One-Step) had performance that was inconsistent. One-Step had performed superior in microleakage while performing poorly in bond strengths which was in agreement with Frankenberger et al. ${ }^{15}$ In general all one-bottle 
systems had lower values when compared with multi-step systems. As explained by others ${ }^{19,20}$, one-bottle adhesives had compromised the wetablity and stability and resulted in poor bonding to tooth structure. In addition, leaving residual water or other solvents could create space which could in turn cause interfacial defects within the hybrid layer and inhibit the infiltration of hydrophobic resin monomer with collagen fibers. ${ }^{16,17,21}$ Therefore, multi-step systems have superior performance results. ${ }^{5,18}$ This could be contributed to primers' solvents evaporation which creates clean tags for bonding agents. ${ }^{13,22}$

Finally, adhesive systems could be expressed as a simple relationship between bonds and stress. If the bonds can withstand the stress, the restoration will be successful. ${ }^{6}$

\section{Conclusion}

Based on the limitations of this study, the following conclusions could be drawn:

1. Different leakage patterns were observed with the different types of dentin bonding agents employed.

2. Scotch Bond Multi-Purpose achieved better sealing ability (less microleakage) and the highest bond strength.

3. One-Step had the least shear bond strength.

4. All-Bond 2 and Perma Quick showed the least sealing ability.

5. There was no relationship between microleakage and shear bond strength. 


\section{References}

1. Baratieri LN, Ritter AV. Four-year clinical evaluation of posterior resin-based composite restorations placed using the total-etch technique. J Esthet Restor Dent. 2001;13(1):50-7.

2. Van Dijken JW, Kieri C, Carlen M. Longevity of extensive class II open-sandwich restorations with a resin-modified glass-ionomer cement. J Dent Res. 1999 Jul;78(7):1319-25.

3. Rosin M, Urban AD, Gartner C, et. al. Polymerization shrinkage-strain and microleakage in dentinbordered cavities of chemically and light-cured restorative materials. Dent Mater. 2002 Nov;18(7): 521-8.

4. Schneider BT, Baumann MA, Watanabe LG, et. al. Dentin shear bond strength of compomers and composites. Dent Mater. 2000 Jan;16(1):15-9.

5. Abdalla Al, Davidson CL. Shear bond strength and microleakage of new dentin bonding systems. Am J Dent. 1993 Dec;6(6):295-8.

6. Van Noort R. Introduction to dental materials. Mosby Publisher, 1994; Page 136.

7. Eliades G. Clinical relevance of the formulation and testing of dentine bonding systems. J Dent. 1994 Apr;22(2):73-81. Review.

8. Miyazaki M, Tsubota $\mathrm{K}$, Onose $\mathrm{H}$, et. al. Influence of adhesive application duration on dentin bond strength of single-application bonding systems. Oper Dent. 2002 May-Jun;27(3):278-83.

9. Stiesch-Scholz M, Hannig M. In vitro study of enamel and dentin marginal integrity of composite and compomer restorations placed in primary teeth after diamond or Er:YAG laser cavity preparation. $J$ Adhes Dent. 2000 Autumn;2(3):213-22.

10. Feilzer AJ, De Gee AJ, Davidson CL. Setting stress in composite resin in relation to configuration of the restoration. J Dent Res. 1987 Nov;66(11):1636-9.

11. Hewlett ER. Resin adhesion to enamel and dentin: a review. J Calif Dent Assoc. 2003 Jun;31(6): 469-76. Review.

12. Leloup G, D'Hoore W, Bouter D, et. al. Meta-analytical review of factors involved in dentin adherence. J Dent Res. $2001 \mathrm{Jul} ; 80(7): 1605-14$.

13. Guzman-Ruiz S, Armstrong SR, Cobb DS, et. al. Association between microtensile bond strength and leakage in the indirect resin composite/dentin adhesively bonded joint. J Dent. 2001 Feb;29(2): 145-53.

14. Schilke R, Bauss O, Lisson JA, et. al. Bovine dentin as a substitute for human dentin in shear bond strength measurements. Am J Dent. 1999 Apr;12(2):92-6.

15. Frankenberger R, Perdigao J, Rosa BT, et. al. "No-bottle" vs "multi-bottle" dentin adhesives--a microtensile bond strength and morphological study. Dent Mater. 2001 Sep;17(5):373-80.

16. Sano H, Takatsu T, Ciucchi B, et. al. Nanoleakage: leakage within the hybrid layer. Oper Dent. 1995 Jan-Feb;20(1):18-25.

17. Li H, Burrow MF, Tyas MJ. Nanoleakage patterns of four dentin bonding systems. Dent Mater. 2000 Jan; 16(1):48-56.

18. Dunn WJ, Soderholm KJ. Comparison of shear and flexural bond strength tests versus failure modes of dentin bonding systems. Am J Dent. 2001 Oct;14(5):297-303.

19. Frankenberger R, Kramer N, Petschelt A. Fatigue behaviour of different dentin adhesives. Clin Oral Investig. 1999 Mar;3(1):11-7.

20. Swift EJ Jr., Wilder AD Jr., May KN Jr., et. al. Shear bond strengths of one-bottle dentin adhesives using multiple applications. Oper Dent. 1997 Sep-Oct;22(5):194-9.

21. Pashely DH, Carvalho RM. Dentine permeability and dentine adhesion. J Dent. 1997 Sep;25(5): 355-72.

22. Armstrong SR, Boyer DB, Keller JC. Microtensile bond strength testing and failure analysis of two dentin adhesives.

Dent Mater. 1998 Jan;14(1):44-50.

23. Retief DH, Mandras RS, Russell CM. Shear bond strength required to prevent microleakage of the dentin/restoration interface. Am J Dent. 1994 Feb;7(1):44-6.

24. Neme AL, Evans DB, Maxson BB. Evaluation of dental adhesive systems with amalgam and resin composite restorations: comparison of microleakage and bond strength results. Oper Dent. 2000 Nov-Dec;25(6):512-9. 

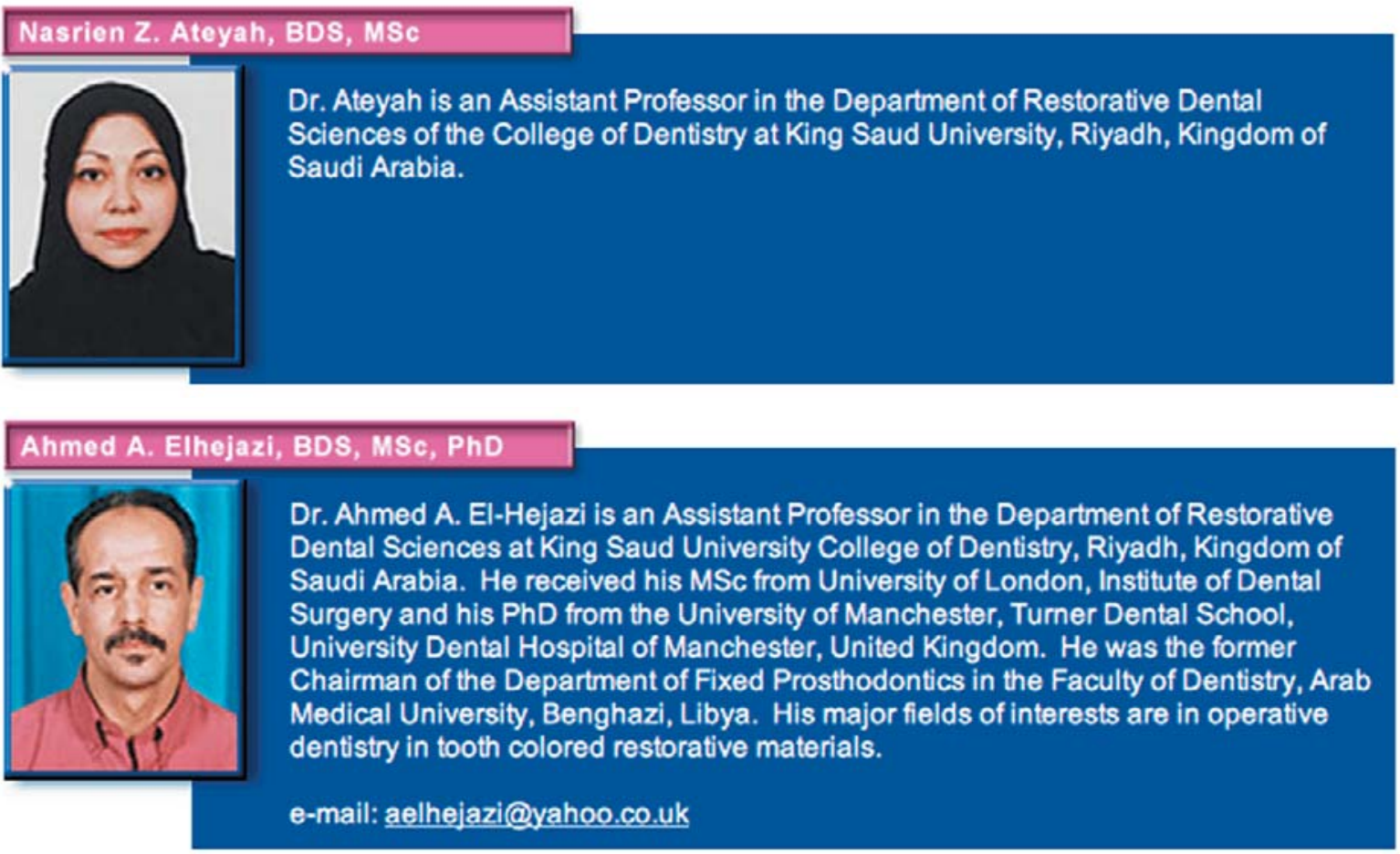